\title{
A CRISE DA TEORIA DAS GERAÇÕES DOS DIREITOS NOS TRATADOS E CONVENÇÕES INTERNACIONAIS
}

\author{
THE CRISIS OF THE GENERATIONS OF RIGHTS THEORY IN \\ INTERNATIONAL TREATIES AND CONVENTIONS
}

\author{
Norton Maldonado Dias ${ }^{1}$
}

\begin{abstract}
RESUMO
O presente trabalho estende a corrente crítica à concepção geracional dos direitos humanos. Trata-se de uma crítica a teoria das Gerações dos Direitos instabilizada no plano da proteção dos Tratados e Convenções Internacionais que ao contrário da concepção geracional não começou pelos direitos civis, políticos. Ocorre que no âmbito internacional a teoria das gerações que abarca os direitos humanos sucumbe quando vislumbrada do ponto de vista dos Tratados e Convenções Internacionais, haja vista que sob o ponto de vista internacional as primeiras proteções de direitos começaram com as Convenções da OIT (Organização Internacional do Trabalho) de 1919, de modo a provocar revisões e novos estudos que apontem fases no surgimento e desenvolvimento dos direitos humanos que considerem o plano internacional.
\end{abstract}

Palavras-chave: Gerações de direitos. Tratados e convenções internacionais. Direitos Humanos

\begin{abstract}
The work extends the critical current to the generational conception of the human right. It is the attempt to extend the critical broach of the Generations of Rights Theory made unstable in terms of protection of International Treaties and Conventions. To broach the emergence of political rights under the contrary perspective of generational conception and taking as a starting point the international concept, where such prerrogatives that got around the citizenship legal protection did not start with civil and political rights. It occurs that in the international sphere, the theory of generations that covers the humans rights succumbs when glimpsed from the International Treaties and Conventions point of view, given that under the international point of view the first rights protections began with the ILO Conventions (International Labour Organization) in 1919, to cause revisions and new studies that point phases in the emergence and development of human's rights that consider the international level.
\end{abstract}

\footnotetext{
${ }^{1}$ Mestrando pelo Centro Universitário Euripedes de Marília. Especialista em Direito pela Universidade Estadual de Londrina.
} 
Keywords: Generations of rights. Treaties and international conventions. Humans rights.

\section{INTRODUÇÃO}

No estudo do Direito Internacional e na sua evolução, não há como ignorarmos o desenvolvimento da questão humana e o seu processo axiológico de maturação, inclusive no âmbito das práticas contemporâneas, judiciárias e na esfera internacional por parte dos seus sujeitos de direito.

Nesse contexto a concepção teórica fortemente aceita corresponde ao pensamento que ficou conhecida como "gerações de direitos", inclusive enfatizando a relevância de publicações da temática, pois a crítica da teoria geracional é ínfima, normalmente, de adeptos internacionalistas, em face de uma construção bastante aceita correspondente a maior parte do numerário de referências bibliográficas, principalmente concernente as obras de Direitos Constitucional.

Não podemos falar em sobrevida da concepção geracional dos direitos fundamentais, pois sua vasta aceitação forma a corrente predominantemente majoritária, tendo em vista o numerário de adeptos, porém aqui vale enfatizarmos a corrente crítica e minoritária formada por muitos autores que revelam os problemas deste pensamento quando vislumbram que o plano dos Tratados e Convenções Internacionais de proteção dos direitos humanos, uma vez que estes não começaram com os direitos civis e políticos, tal como aponta o ideário geracional, mas sim pelas primeiras tutelas de proteções dos direitos sociais do trabalho de 1919, ou seja, há uma manifesta inversão ou ruptura na proposta geracional quando fazemos verificação científica de documentos de outros planos de proteção que não o da esfera interna ou constitucional.

O trabalho demonstra que o idealizador da concepção teórica geracional, Karel Vasak, pautou-se no lema revolucionário francês para apontar as primeiras gerações destas prerrogativas, ou seja, a proposta teórica se conforma em um sedutor lema revolucionário, justamente, pela estética humanista que a concepção seduz.

Ocorre que não há credibilidade científica no critério irracional de usar o romantismo de um lema revolucionário como regra sequencial obrigatória pela qual desenvolveu as prerrogativas tidas como humanas, de sorte que a revisão desta construção 
teórica é um contingente necessário, haja vista sua enorme influencia dentro da comunidade científica.

A prova desta necessidade e da instabilidade sequencial do desenvolvimento deste direito pode ser vislumbrada do ponto de vista da tutela internacional destes direitos que não acompanharam a mesma sequencia evolutiva apontada pelos documentos constitucionais e para tal basta confrontá-los com documentos internacionais, começando pelas primeiras proteções relativas a pessoa no plano internacional que corresponde as Convenções da OIT (Organização Internacional do Trabalho) de 1919 e não pelos direitos civis e políticos como propõe a teoria.

Portanto, de fato, há um grande problema nessas proteções que ficaram conhecidas como gerações de direitos, de sorte manifesto descompasso do processo de desenvolvimento e maturação destes direitos na tutela jurídica interna em detrimento a tutela jurídica internacional.

Por isso é que existe a necessidade e o contingente que clama por estudos dos direitos fundamentais e humanos que respondam a lacunas relativas ao processo de evolução histórica, de conquistas de suas garantias, partindo de um ponto de vista racional e que levem em considerações critérios científicos com maior exatidão a essas indagações causadoras de grandes incertezas e inseguranças quando toca em pensamentos tão bem aceitos, divulgados e que tem se demonstrado bastante significativos por vários literários da dogmática jurídica na atualidade.

\section{DA GERAÇÃO DOS DIREITOS À CIDADANIA SOB A ÓTICA DOS TRATADOS E CONVENÇÕES INTERNACIONAIS}

Dentro da crítica do pensamento geracional, encontramos certas adaptações terminológicas, tais como, o uso da expressão dimensões em substituição a ideia de gerações. As razões para a correção no uso da expressão “dimensão” já é, per si, um defeito na concepção teórica, posto que a ideia de geração não admite o acréscimo dos direitos de uma fase com os direitos da fase precedente.

Assim, a concepção geracional já ofende características peculiares dessas prerrogativas relativas à pessoa, pois ofende a inerauxibilidade e indivisibilidade desses direitos, quando a proposta do termo "geração” pressupõe subtração da fase precedente. Podemos, inclusive, dizer que a correção não era meramente terminológica, mas 
ontológica, pois tocava aspectos peculiares destas prerrogativas, tais como, os já reiterados da inexauribilidade e indivisibilidade.

No geral as ideias geracionais ou dimensionais dizem respeito a muitos dos mais importantes direitos da pessoa humana, como forma de dar contornos precisos sobre as mais importantes prerrogativas relativas à pessoa humana e no curso desta tramitação tivemos as diversas fases, dentre as quais, a chamada primeira geração de direitos referente aos direitos civis e políticos, uma segunda geração de direitos que referem-se aos direitos de segunda geração e, para encerrar, os direitos de terceira geração referente a fraternidade como termo que encerra o lema revolucionário francês. Não podemos esquecer que existem doutrinas que falam em até sexta ou sétima geração e direitos.

Exatamente, por isso, é que o pensamento sucumbe pela própria doutrina de aceitação quando se percebe que a expressão terminológica "geração" é inadequado para apontar fases de uma processo evolutivo, posto que os direitos de uma fase precedente ão deixam de existir em razão da fase posterior, tratam-se de prerrogativas que vão acrescendo no histórico de evolução desses direitos.

O mais curioso é que a percepção do erro pela doutrina de aceitação não teve a suficiência para repugnar o pensamento, de sorte que a opção declinou por uma proposta terminológica de adequação, tratando essas fases evolutivas não mais como geração, mas sim como “dimensão” de direitos. Salienta-se que o erro não era meramente terminológico, mas ontológico, posto que no estudo dessas prerrogativas existem alguns aspectos que são características peculiares destes direitos, dentre os quais, inexauribilidade.

O majoritarismo da literatura jurídica nacional, principalmente, concernente ao Direito Constitucional, trouxe várias discussões em meio as celeumas no que tange a temática, inclusive divergências entre o idealizador do pensamento, Karel Vssak, e o maior defensor dela no Brasil, o cientista político Paulo Bonavides:

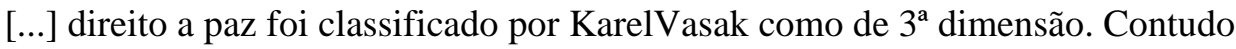
Paulo Bonavides entende que o direito à paz deva ser tratado em dimensão autônoma, chegando a afirmar que a paz é axioma da democracia participativa, ou, ainda, supremo direito da humanidade. (BONAVIDES, 1998, p. 593).

Em que pese a idealização teórica sem os devidos critérios da metodologia científica e o pensamento ter sido elaborado por Karel Vasak, a literatura responsável pelo projeção atual do pensamento correspondente a obra intitulada “A Era dos Direitos” de Nobberto Bobbio e a tentativa originária do pensamento que foi classificar fases 
metodológicas no estudo dos direitos fundamentais baseado no lema revolucionário setecentista francês, Liberté, Égalité, Fraternité (Révolution Française, 1789-1799).

Portanto, não podemos ignorar, na perspectiva de primeiro transcrever o pensamento, para só depois criticá-lo, mencionar a obra “A Era dos Direitos” (BOBBIO, Nobberto), haja vista ser desta obra a principal responsabilidade pela repercussão que hoje ganha tamanha aceitação dentro da literatura jurídica e doutrina nacional.

A doutrina defensora desta corrente no Brasil começou com o jurista Paulo Bonavides, considerado o maior defensor da corrente que baseou-se na obra responsável pela projeção internacional do pensamento, ou seja, a reiteração menção de Nobberto Bobbio com a obra intitulada “A Era dos Direitos”. Porém, releva-se a menção do histórico idealizador cujas autoria é atribuída a um jurista naturalizado na França, chamado Karel Vasak, uma vez que o próprio idealizador do pensamento, Karel Vasak, admitiu relacionar o desenvolvimento e processo histórico e evolutivo dos direitos relativos a pessoa com o lema revolucionário francês de 1789.

Sendo o campo que justifica as falhas do pensamento, pois a hipótese do remendo terminológico com a expressão “dimensão” e a ruptura da ordem proposta quando vislumbrada por diferentes esferas de proteção são causadas, justamente, pelo fato do pensamento ter arriscado o fundamento no critério romântico e sedutor que leva consigo todo discurso humanista, ainda mais quando cumula a estética de um lema ideário de uma Revolução, tal como foi a da França de 1789.

Por isso que a necessidade que reitera a falta de razões que justifiquem direitos tão importantes dentro do estudo dos direitos fundamentais, tais como, liberdade de expressão ou direito de voto das mulheres, por exemplo, estarem lógica e obrigatoriamente atrelado com um lema revolucionário.

Portanto, a questão investigatória de concluir pelas fases metodológicas e históricas de uma determinada categoria de direitos deveria ser concluída com base em justificativas e critérios políticos, filosóficos, sociológicos, comparando e relacionando a previsão dessas prerrogativas em documentos históricos com os contextos históricos que vão se desenvolvendo, de modo a aproximar o pensamento da metodologia científica, de sorte que o critério da relação com um lema revolucionário não deixa de ser aleatório e arrisca críticas e defeitos quando não conseguem ser demonstráveis do ponto de vista de outros planos de proteção, tais como, os documentos históricos de tutela de proteção internacional. 
Em que pese esse pensamento seja majoritariamente influente pela doutrina jurídica, vale a demonstração de uma significativa corrente que vem crescendo e composta, em sua maioria, por internacionalistas que ao vislumbrarem as documentações responsáveis pelo desenvolvimento dos mesmos direitos, porém sob o ponto de vista da tutela internacional concluem que a proposta sequencial base da concepção teórica geracional, ou mesmo dimensional que cumulam as conquistas precedentes em termos de prerrogativas, não se verificam quando verificadas do ponto de vista do processo evolutivo que se desenvolveu no campo jurídico internacional.

A proposta releva a crítica de desconstrução da teoria das gerações de direitos como um importante efeito não só na mudança de todo um pensamento influente nas diversas bibliografias jurídicas nacionais, mas na provocação de estudos mais comprometidos com o critério científico metodológico do processo de evolução e desenvolvimentos dos direitos da pessoa e não restrito ao romantismo de lema francês revolucionário setecentista.

A insistência dos teóricos da normalidade, dos direitos fundamentais e humanos não questionarem, por exemplo, a ordem sequencial de fases do surgimento, desenvolvimento e previsão desses direitos, quando vislumbrado sob outros planos de proteção que não tão somente os constitucionais, de sorte que, não surpreendentemente, verificarão sob o ponto de vista do processo de proteção internacional que primeiro se protegeu os direitos tidos como de segunda geração e somente após os Tratados e Convenções Internacionais de 1919 relativas ao trabalho é que se preocupou com a proteção dos direitos civis e políticos (em tese estes direitos deveria preceder aqueles, haja vista serem de primeira geração/ dimensão).

O tema tem exigido aprofundamentos, porém os pensamentos também possuem seus aspectos agradáveis que convencem e irradiam paixões, ainda mais quando se trata de uma evolução humanista pautada no romantismo de lema revolucionário clássico oriundo de contexto francês setecentista. Ao invés do comprometimento científico a doutrina trabalha com remendos de adequações e a correção terminológica de "geração" para “dimensão” é um pouco deste repúdio em desmentir uma destas estéticas sedutoras do pensamento.

O cientista deve trabalhar, por excelência, sob a ótica do que chamamos de método científico e a verificação que classificou as fases metodológicas e históricas de importantes prerrogativas, hoje previstas nos documentos constitucionais que estruturam os 
diferentes Estados em face do processo de proteção por outros documentos que não os constitucionais, tais como, os Tratados e Convenções Internacionais.

O jurista idealizador desses pensamentos geracionais, Karel Vasak, nasceu na Tchecoslováquia e possui uma formação europeia, especificamente, na França onde estudou Direito, naturalizou-se, em razão da invasão soviética de 1968, e ocupou importantes cargos, tais como, de primeiro secretário-geral do Instituto Internacional de Direitos Humanos em Estraburgo.

Logicamente que as ideias de gerações de direitos são relevantes, posto que contextualizam historicamente muitos dos mais importantes direitos da pessoa humana como uma forma de delinear não só o desenvolvimento, mas também o surgimento dessas prerrogativas, tais como, direitos civis e políticos contextualizados em um primeiro momento que a teoria chamou de primeira geração; ou mesmo os direitos sociais, econômicos e culturais como pertencentes a uma segunda geração, demonstrando posterioridade de cada momento histórico em que os direitos da pessoa humana se desenvolveram, ou seja, um processo evolutivo contínuo de maturação. Também, vale ressaltar que essas ideias de gerações sempre partiram do plano do Direito interno, principalmente do Direito Constitucional.

Porém falhas teóricas são salutares a começar com a contextualização dos primeiros direitos protegendo seres humanos que no plano internacional começaram com as Convenções da OIT (Organização Internacional do Trabalho) de 1919. Essas Convenções foram celebradas muito antes de surgir, no plano do Direito Internacional os chamados “direitos civis e políticos”, categoria que a Teoria Geracional apontou como sendo de primeira geração, mas que no plano internacional só apareceram em 1966 (Pacto de Direitos Civis e Políticos), ou seja, muito tempo depois das Convenções do Trabalho de 1919.

Portanto, a teoria não se verifica a luz da ótica internacional, pois os primeiros tratados e convenções internacionais que cuidaram dos seres humanos (referente a natureza dos direitos objeto da Teoria Geracional) correspondem as Convenções do Trabalho de 1919, ou seja, direitos referentes a segunda geração, de modo que admiti-la no plano internacional seria o mesmo que admitir a anomalia ilógica de uma segunda geração antes da primeira.

Assim, temos que provocar estudos que reconheçam as falhas ou a quebra das ideias de geração dos direitos desenvolvidas até a atualidade, haja vistas as respectivas 
implicâncias nos estudos e pesquisas sobre o surgimento histórico dos mais importantes direitos fundamentais que já se concluíram até então. Tais como, os direitos fundamentais de liberdade, os direitos políticos, os direitos econômicos e de ordem social, dentre tantos que tiveram seu surgimento compreendido a partir de um mesmo contexto histórico que a teoria determinou através da ideia de geração e que, curiosamente, no plano internacional não se verifica.

Porém, vale aqui ressaltar que esta crítica não é inédita, nem mesmo inaugural, em que pese minoritária, releva-se os muitos renomes que contornam esta linha, dentre os quais, (desfavorável a teoria das gerações de direitos), Flávia Piovesan, Valério Mazzuoli, Cançado Trindade, Jairo Schäfer e, talvez seu maior crítico, Carlos Weis, sem contar com autores de menores projeções que também se posicionaram de maneira inserida na corrente contraria ao sistema geracional dos direitos humanos e fundamentais.

E os defeitos apontados pelo pensamento geracional/ dimensional pela própria adaptação dos defensores que tentaram evoluções terminológicas em detrimento a máculas ontológicas da teoria, fazendo referência a expressão "geração", uma vez que o termo não era fiel ao trazer consigo certo aspecto sucessório inerente da expressão. Como se os direitos fossem sucedendo uns pelos outros, uma geração sucedida pela outra, entrando em choque com características básicas dos direitos humanos, tais quais, indivisibilidade ou inexauribilidade. Por isso a famosa proposta que inovou a terminologia para "dimensões do direito".

Podemos destacar que, em que pese uma aparente carência de abordagem sobre o assunto em face de gigantesca construção bibliográfica que declina mais a corrente interna constitucional, favoráveis as correntes geracionais, vale trazermos e divulgarmos a bibliografia contrária, dentre as quais, a obra "Direitos Humanos Contemporâneo" (WEIS, 2010); “Teoria Geral dos Direitos Humanos na Ordem Internacional”(RAMOS, 2013); “Classificação dos Direitos Fundamentais: do Sistema Geracional ao sistema unitário Uma proposta de Compreensão” (SCHÄFER, 2005); “Curso de Direito Internacional Público” (MAZZUOLI, 2013) e tantos outras literaturas e estudos que podem servir de orientação e perspectivas teóricas a respeito de um significativo trabalho a ser desenvolvido por qualquer patrocínio acadêmico que seja, enfatizando sempre ser esta o pensamento minoritário.

Vale, inclusive a citação bibliográfica de internacionalista bastante populares do Direito Internacional, tal como Mazzuoli (2013, p. 858): 
[...] a consagração nas Constituições dos direitos sociais foi, em geral, posterior à dos direitos civis e políticos, ao passo que no plano internacional o surgimento da Organização Internacional do Trabalho, em 1919, propiciou a elaboração de diversas convenções regulamentando os direitos sociais dos trabalhadores, antes mesmo da internacionalização dos direitos civis e políticos no plano externo.

A corrente crítica e contrária a linha geracional possuem orientação teórica que podemos buscar em autores como(desfavorável a teoria das gerações de direitos), Flávia Piovesan, Valério Mazzuoli, Cançado Trindade, Jairo Schäfer e, talvez seu maior crítico, Carlos Weis, sem contar com autores de menores projeções que também se posicionaram de maneira inserida na corrente contraria ao sistema geracional dos direitos humanos e fundamentais.

As obras que podem ser referenciadas para provocações acadêmicas que possam contribuir para uma revisão científica do processo evolutivos dos direitos relativos a pessoa humana são, dentre outras, a obra "Direitos Humanos Contemporâneo”; “Teoria Geral dos Direitos Humanos na Ordem Internacional”; “Classificação dos Direitos Fundamentais: do Sistema Geracional ao sistema unitário - Uma proposta de Compreensão"; "Curso de Direito Internacional Público”.

Também podemos trazer algo bastante curioso desta literatura como a expressão deste pensamento crítico de Cançado Trindade (2013) que reitera sua crítica contra a teoria geracional no prefácio da obra professora Flávia Piovesan (2002), de modo que podemos garantir fontes bibliográficas bastantes significativas no caminhar de aprofundamentos mais precisos sobre a matéria.

O principal objetivo deste trabalho é provocar reflexões nos estudos dos direitos humanos e fundamentais, considerando concepções que uniformizassem o plano interno e internacional. Repensando o processo histórico de desenvolvimento dos planos de proteção dos direitos referentes a pessoa humana que não seja excludente ou denegatória de outras óticas protetivas no histórico de tutelas e prerrogativas.

A Teoria das Gerações de Direitos tem sido critério de regime de verdade na dogmática jurídica, de sorte que não só nas obras literárias, mas também frequentemente vislumbrado em gabaritos e exames públicos nas mais diversas carreiras jurídicas e no discurso de tantos anos no cotidiano dos profissionais da área e nas aulas do magistério.

Assim, faz-se necessário fomentar a ideia e o pensamento imprescindível de comparar e relacionar as investigações realizadas nos diversos contextos de proteção no 
plano interno e, também, no plano internacional, ousando conclusivos que expliquem as razões históricas, científicas e sociológicas para que Constituições dos Estados e Tratados e Convenções Internacionais não seguirem o mesmo processo de proteção de direitos referentes a pessoa.

As provocações deve se comprometer com critérios do método científico e não com sedutoras linhas idealização em lemas revolucionários humanistas que, de fato, apaixonam os autores e juristas e, por outro lado, deve comprometer-se, também, com um pensamento que, no mínimo, ouse a uniformização ou abrangência no pensamento de apenas uma ótica protetiva, restrita a acompanharem uma única ordem sequencial lógica que abarquem todos os planos de proteção e não falhe quando seja vislumbrada de outro modo, pois a sustentabilidade de um pensamento teórico é, justamente, resguardar a mesma lógica nos diferentes pontos de vista e para isso o método científico é imprescindível na verificação do processo de surgimento e desenvolvimento das mais relevantes prerrogativas concernentes aos direitos humanos e fundamentais.

\section{CONSIDERAÇÕES FINAIS}

A proposta não é apenas de desconstrução do pensamento geracional, mas de revisão do pensamento com base em falhas da sua própria construção, dentre as quais, os remendos na expressão intituladora do pensamento que tenta aparentar mera questão terminológica, quando na verdade trata-se de problemática ontológica da teoria, além da principal crítica correspondente a ruptura que sofre a concepção teórica das gerações de direitos quando observada do ponto de vista da tutela internacional dessas mesmas prerrogativas que não observam a ordem proposta pelos constitucionalistas.

O trabalho busca ajudar projeção da necessidade de uniformização dos planos de proteção no estudo do histórico dos direitos humanos, de forma que vislumbre de maneira uniforme a abrangência de toda a esfera de proteção e não só restrita a documentos constitucionais, atrelando aos critérios do método científico e não pautados na estética romântica e humanista de lema francês revolucionário.

Por isso é que vale estudos como forma de divulgar a orientação bibliográfica da corrente crítica, em que pese ainda minoritária, mas com significativo numerário de autores renomados que podem dar sustentabilidade a estudos nesse sentido, dentre os quais (desfavorável a teoria das gerações de direitos), Flávia Piovesan, Valério Mazzuoli, 
Cançado Trindade, Jairo Schäfer e, talvez seu maior crítico, Carlos Weis, relevando uma crítica ou, até mesmo, conclusivos de um trabalho que signifique a desconstrução da Teoria das Gerações dos Direitos teria consequências em todo um pensamento que ganhou aceitação em grande parte das ciências jurídicas no decorrer dos anos.

A proposta tem por base, justamente, a inovação dos estudos sobre a crítica da teoria geracional por meio de recortes históricos no plano de proteção internacional dos direitos relativos à pessoa humana em detrimento aos momentos de proteção desses mesmos direitos nas Constituições dos Estados. Com isso, busca-se o comparativo, os apontamentos precisos sobre razões que levaram o apontado descompasso e a quebra verificável no histórico de proteção dos documentos no plano dos Tratados e Convenções Internacionais em detrimento ao histórico desta mesma tutela ocorrida no plano constitucional e interno do Direito.

Revela-se a necessidade de estudos incisivos nessa área lacunosa, caracterizada por inexatidões e admitindo rupturas na consideração de outros planos de proteção no decorrer do processo de evolução das tutelas dessas prerrogativas, de sorte que há, de fato, uma necessidade de reconhecer a lacuna e preenche-la com uma evolução histórica de proteção dos direitos referentes a pessoa que, de fato, abarque outras esferas do direito.

Portanto, o trabalho provoca reflexões, concluindo pela ruptura de um processo histórico de proteção que sucumbe quando deixa de considerar documentos de natureza constitucional e passa a oscilar quando tenta buscar a mesma ordem proposta com base na analise de outros tipos documentais atrelados ao plano de proteção internacional, criando a necessidade de um ponto de vista que se utilize do método científico no processo de proteção da categoria mais relevante de prerrogativas e que tem se assentado em um histórico de maturação e desenvolvimento com base no sedutor lema humanista e revolucionário francês.

\section{REFERÊNCIAS}

ACCIOLY, Hildebrando. Manual de direito internacional público. Atualização de Geraldo Eulálio do Nascimento e Silva e Paulo Borba Casella. 17. ed. São Paulo: Saraiva, 2009.

.Manual de direito internacional público.Atualização de Geraldo Eulálio do Nascimento e Silva e Paulo Borba Casella. 19.ed.São Paulo: Saraiva, 2011. 
ALEXY, Robert.Teoria dos Direitos Fundamentais. Tradução Luíz Virgílio Afonso da Silva. São Paulo: Malheiros, 2008.

BOBBIO, Noberto. A era dos direitos. Tradução Carlos Nelson Coutinho. Rio de Janeiro: Campus, 1992.

BONAVIDES, Paulo. Curso de direito constitucional. 7. ed. São Paulo: Malheiros, 1998.

CANÇADO TRINDADE, Antônio Augusto. A interação entre direito internacionale o ireitointerno na proteção dos direitos humanos. Arquivos do Ministério da Justiça, Ano 46, n. 12, jul/dez. 1993.

.Tratado de direito internacional dos direitos humanos. Porto Alegre: Sergio Antonio Fabris Editor, 2003.

FAVOREU, Louis; RUBIO LLORENTE, Francisco.EI bloque de la constitucionalidade: simposium franco-español de derecho constitucional. Madrid ; Servilla: Civitas; Universidad de Servilla, 1991, 203. P.

GÓMES ROBLEDO, A. Fundadores delderecho internacional, México: UNAM, 1989. P. 48-55.

MAZZUOLLI, Valério de Oliveira. Curso de direito internacional público. 7. ed. São Paulo: Revistas dos Tribunais, 2013, p. 858.

MELLO, Celso D. Albuquerque. O §2o do art. 50 da Constituição Federal. In TORRES, Ricardo Lobo. (Org.). Teoria dos direitos fundamentais. 2. ed. Rio de Janeiro: Renovar, 2001. p. 25.

MORAES, Alexandre de. Direito constitucional. 19. ed. São Paulo: Atlas,2006.

NOVELINO, Marcelo. Manual de direito constitucional. 8. ed. São Paulo: Método, 2013.

PIOVESAN, Flávia. A Constituição Brasileira de 1988 e os tratados internacionais de proteção aos direitos humanos. In: Temas de direitos humanos. 2. ed. São Paulo: Max Limonad, 2003. p. 44-56.

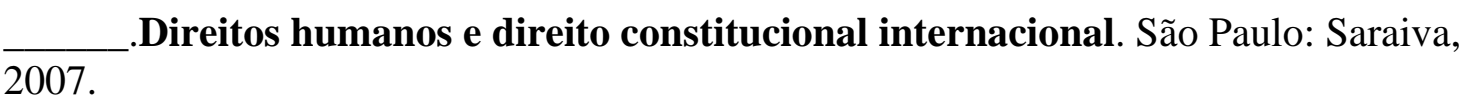

Direitos humanos e o direito constitucional internacional. 5. ed. São Paulo: Max Limonad; 2002.

RAMOS, André Carvalho Teoria geral dos direitos humanos na ordem internacional. 3. ed. São Paulo: Saraiva, 2013.

REZEK, José Francisco. Direito internacional público: curso elementar. 9. ed. São Paulo: Saraiva, 2002. 
SCHÄFER, Jairo. Classificação dos direitos fundamentais: do sistema geracional ao sistema unitário: uma proposta de compreensão. Porto Alegre: Livraria do Advogado, 2005.

SILVA, José Afonso. Curso de direito constitucional positivo. 26. ed. São Paulo: Malheiros, 2006.

WEIS, Carlos. Direitos humanos contemporâneo. 2. ed. São Paulo: Malheiros, 2010.

WIKIPEDIA. Tratado. Disponível em: < http://pt.wikipedia.org/wiki/Tratado $>$. Acesso em: 10 abr. 2014. 